\title{
Clinical characteristics of dry eye with ocular neuropathic pain features: comparison according to the types of sensitization based on the Ocular Pain Assessment Survey
}

\author{
Jonghwa Kim ${ }^{1}$, Hyeon Jeong Yoon ${ }^{1}$, In Cheon You ${ }^{2}$, Byung Yi Ko ${ }^{3}$ and Kyung Chul Yoon ${ }^{1 *}$ id
}

\begin{abstract}
Background: To compare the clinical characteristics of dry eye patients with ocular neuropathic pain features according to the types of sensitization based on the Ocular Pain Assessment Survey (OPAS).

Methods: Cross-sectional study of 33 patients with dry eye and ocular neuropathic pain features. All patients had a comprehensive ophthalmic assessment including detailed history, the intensity and duration of ocular pain, the tear film, ocular surface, and Meibomian gland examination, and OPAS. Patients with < 50\% improvement in pain intensity after proparacaine challenge test were assigned to the central-dominant sensitization group (central group) and those with $\geq 50 \%$ improvement were assigned to the peripheral-dominant sensitization group (peripheral group). All variables were compared between the two groups.

Results: No significant differences were observed in age, sex, underlying diseases, history of ocular surgery, duration of ocular pain, tear film, ocular surface and Meibomian gland parameters (all $p>0.05$ ). Ocular pain and non-ocular pain severity and the percentage of time spent thinking about non-ocular pain were significantly higher in the central group than in the peripheral group (all $p<0.05$ ). Central group complained more commonly of a burning sensation than did the peripheral group $(p=0.01)$.
\end{abstract}

Conclusions: Patients with central-dominant sensitization may experience more intense ocular and non-ocular pain than the others and burning sensation may be a key symptom in those patients.

Keywords: Ocular pain, Ocular neuropathic pain, Neuropathic corneal pain, Neuropathic ocular pain, Dry eye, Sensitization

\section{Background}

Dry eye disease (DED) is a multifactorial disease and the management of DED is often complicated because the disease varies from patients to patients, both in severity

\footnotetext{
* Correspondence: kcyoon@jnu.ac.kr

'Department of Ophthalmology, Chonnam National University Medical School and Hospital, Gwangju, South Korea

Full list of author information is available at the end of the article
}

and in character [1]. DEWS II report has classified ocular neuropathic pain as another entity differentiated from DED [2]. However, some studies reported that patients diagnosed with dry eye often describe features of neuropathic pain, including spontaneous pain, dysesthesias, allodynia, and hyperalgesia [3, 4]. It is established that ongoing damage to the corneal surface and nerve endings induced by tear film instability and persistent

(c) The Author(s). 2020 Open Access This article is licensed under a Creative Commons Attribution 4.0 International License, which permits use, sharing, adaptation, distribution and reproduction in any medium or format, as long as you give appropriate credit to the original author(s) and the source, provide a link to the Creative Commons licence, and indicate if changes were made. The images or other third party material in this article are included in the article's Creative Commons licence, unless indicated otherwise in a credit line to the material. If material is not included in the article's Creative Commons licence and your intended use is not permitted by statutory regulation or exceeds the permitted use, you will need to obtain permission directly from the copyright holder. To view a copy of this licence, visit http://creativecommons.org/licenses/by/4.0/. The Creative Commons Public Domain Dedication waiver (http://creativecommons.org/publicdomain/zero/1.0/) applies to the data made available in this article, unless otherwise stated in a credit line to the data. 
inflammation can cause peripheral neuronal sensitization, and repeated peripheral nerve injury can lead to central neuronal sensitization [5-9]. Topical anesthetic may be insufficient to alleviate pain in patients with centralized ocular neuropathic pain. Crane et al. [10] have introduced the proparacaine challenge test which can discriminate if there is a centralized component in ocular pain.

There is no gold standard for diagnosing ocular neuropathic pain. Owing to the scarcity of available signs, the diagnosis mainly depends on clinical history, symptoms, and ophthalmologic examination results [11, 12]. Many studies attempted to evaluate patients with ocular neuropathic pain with dry eye related questionnaires, such as the Ocular Surface Disease Index, Dry Eye Questionnaire, and Dry Eye-Related Quality-of-Life Score [1315]. The Ocular Pain Assessment Survey (OPAS) is a validated questionnaire for ocular pain and assesses nonocular pain, quality of life (QoL), aggravating factors and associated factors as well [16].

In this study, we collected clinical data and the OPAS questionnaires from three eye centers to investigate the characteristics of patients with DED and ocular neuropathic pain features, the association of ocular neuropathic pain features with pre-existing medical conditions, and the clinical differences between groups classified according to the dominant types of sensitization.

\section{Methods}

A multicenter, cross-sectional study was performed between January 2, 2018 and June 30, 2019, at the outpatient departments of three eye centers in Korea, namely, Chonnam National University Hospital, Konyang University Hospital, and Chonbuk National University Hospital. Informed consent was obtained from each patient. Ethical approval was obtained from the ethical committees of all participating hospitals, and the study protocol followed the guidelines of the Declaration of Helsinki.

\section{Patients and groups}

Patients complaining of continuous severe ocular pain or burning sensation of pain score 7 or more using the Wong-Baker FACES ${ }^{\circ}$ Pain Rating Scale with little or no corneal staining were included. The diagnosis of DED was made based on DEWS II criteria [2]. Patients who complained of ocular discomfort and had tear film break-up time (TBUT) less than $10 \mathrm{~s}$ were included. Patients with active inflammation of ocular surface and eye lid, orbital diseases that could induce pain, glaucoma, and migraine were excluded. Patients with deficient tear secretion with Schirmer test scores less than $5 \mathrm{~mm} / 5$ min without anesthesia were also excluded.
Patients were divided into two subgroups according to their response to the proparacaine challenge test $[6,10]$. As part of the test, $10 \mu \mathrm{L}$ of $0.5 \%$ proparacaine hydrochloride (Alcaine, Alcon, Fort Worth, TX, USA) was instilled in the inferior fornix of each eye. The WongBaker FACES ${ }^{\circ}$ Pain Rating Scale scores (range, 0-10) were recorded before and $15 \mathrm{~s}$ after proparacaine administration. Patients with more than a 50\% decrease in pain scores after $15 \mathrm{~s}$ were assigned to the peripheraldominant sensitization group (peripheral group) and those with a decrease in pain scores equal to or less than $50 \%$ were assigned to the central-dominant sensitization group (central group). Information on demographics and thorough history of systemic diseases and ocular surgery was collected for each patient.

\section{Tear film, ocular surface, and Meibomian gland assessment}

TBUT, Schirmer test score, and corneal staining score (CSS) were evaluated by three cornea specialists (K.C.Y, I.C.Y, and B.Y.K) at the first visit. TBUT was assessed three times after the instillation of fluorescein dye, and the mean TBUT recorded in seconds was used for analysis. CSS was evaluated subsequently by employing a white light and cobalt blue filter, using the area-density index, scoring the area $(0-3)$ and density $(0-3)$ of the superficial punctate corneal lesion, and multiplying the area and density scores (0-9) [17]. The Schirmer test was performed using a calibrated sterile strip (Color Bar Schirmer Tear Test, Eagle Vision Inc., Memphis, TN, USA) under topical anesthesia $(0.5 \%$ proparacaine hydrochloride). The sterile strips were placed in the lateral canthus, away from the cornea, for $5 \mathrm{~min}$ with the eyes closed. Schirmer test scores were recorded in millimeters of wetting after 5 min.

The Meibomian gland (MG) expressibility was assessed by applying digital pressure onto the lower central eyelid and counting the number of expressed gland orifices within the central eighth of the lower eyelid and was scored on a $0-3$ grading scale [18]. MG secretion quality score was also assessed using a $0-3$ grading scale [18]. The eye with worse pain was chosen for statistical analysis for each patient because the OPAS questions are conducted on the eye with more pain [16]. When both eyes had the same pain intensity, the values from the right eye were included in the analysis.

\section{Ocular pain assessment}

All patients completed the OPAS, which is a validated questionnaire for neuropathic pain that combines patient responses regarding ocular and non-ocular pain intensity, impact on QoL, aggravating factors, associated factors, and symptomatic relief [16]. The questions were divided into sections for analysis: questions 4-9 
pertained to the intensity of ocular pain; questions 10 12 , non-ocular pain; questions $13-19$, the QoL; questions 20-21, aggravating factors; and questions 22-25, associated factors. After excluding the section on symptomatic relief, only questions $4-25$ were analyzed in this study.

\section{Statistical analysis}

SPSS Statistics for Windows, Version 23.0 (IBM Corp., Armonk, NY, USA) was used for statistical analysis. All data are shown as the mean \pm standard deviation. The Kolmogorov-Smirnov test was performed for continuous variables, and the normally distributed variables were age, OPAS ocular pain intensity score, impairment in walking score, pain-associated redness, and burning sensation score. The independent $\mathrm{t}$-test was used to identify between-group differences in the mean values of these variables. For other variables that were not normally distributed, the Mann-Whitney U-test was performed. Pearson's correlation analysis between the Wong-Baker FACES $^{\circ}$ Pain Rating Scale and the ocular pain severity score of OPAS was conducted. A $p$ value $<0.05$ was considered statistically significant. The sample size of 17 subjects in the central group and 16 subjects in the peripheral group provided approximately $88 \%$ of power to show a significant difference with the independent t-test.

\section{Results}

A total of 33 patients were analyzed. On the basis of the proparacaine challenge test results, 17 patients were assigned to the central group and 16 patients to the peripheral group; their mean ages were $59.12 \pm 11.58$ and $58.13 \pm 12.86$ years, respectively. There were more women than men in both groups. Table 1 shows the demographic features and personal history of the patients. Two patients in the central group and one in the peripheral group had been diagnosed with chronic pain syndrome (CPS). In the central group, two patients had psychological disorders and two others had neurological disorders, whereas in the peripheral group, none had psychological or neurological disorders. Six patients in the central group and three in the peripheral group had previous cataract surgery. No significant differences were observed in the demographic and personal history data between the two groups (all $p>0.05$ ).

The mean values for TBUT, Schirmer test score, CSS, and MG quality and expressibility in patients with ocular neuropathic pain were $4.67 \pm 2.01 \mathrm{~s}, 7.22 \pm 5.09 \mathrm{~mm}$, $0.42 \pm 0.75,1.21 \pm 0.82$, and $0.61 \pm 0.79$, respectively. No significant differences were found in tear film, ocular surface, and MG parameters between the central and peripheral groups (all $P>0.05$ ) (Table 2). The duration of ocular pain was $38.35 \pm 31.37$ months in the central group and $36.00 \pm 30.54$ months in the peripheral group but the difference between groups was not significant $(p=0.69)$.

Table 3 summarizes the OPAS scores in the participants. The ocular pain severity score was significantly higher in the central group $(36.71 \pm 11.48)$ than in the peripheral group $(25.06 \pm 11.21) \quad(p<0.01)$. The pain scale assessed by the Wong-Baker FACES ${ }^{\circ}$ Pain Rating Scale was also significantly higher in the central group $(7.06 \pm 2.33$ vs. $5.19 \pm 2.56, p=0.04)$ and the Pearson's correlation coefficient between the Wong-Baker FACES ${ }^{\circ}$ Pain Rating Scale and the OPAS score was $0.78(p<$ 0.001). Non-ocular pains, such as headache, backache, and arthralgia, scored higher in the central group $(6.12 \pm 3.12)$ than in the peripheral group $(3.81 \pm 2.90$,

Table 1 Demographics of dry eye patients with ocular neuropathic pain features

\begin{tabular}{llll}
\hline & All & Types of sensitization & Peripheral $(\boldsymbol{N}=\mathbf{1 6})$ \\
\cline { 2 - 3 } & & Central $(\boldsymbol{N}=\mathbf{1 7})$ & $58.13 \pm 12.86$ \\
Demographics & & & 6.10 \\
Age (years) ${ }^{\text {a }}$ & $58.64 \pm 12.03$ & $59.12 \pm 11.58$ & $6(37.5)$ \\
Sex (M:F) & $12: 21$ & $12(70.6)$ & $5(31.3)$ \\
Hypertension & $18(54.5)$ & $4(23.5)$ & $1(6.3)$ \\
Chronic pain syndrome & $9(27.3)$ & $2(11.8)$ & $0(0)$ \\
Diabetes mellitus & $3(3.1)$ & $2(11.8)$ & $0(0)$ \\
Neurologic disorder & $2(6.1)$ & $2(11.8)$ & $0(0)$ \\
Psychological disorder & $2(6.1)$ & $2(11.8)$ & $4(25.0)$ \\
Ocular Surgery, $n$ (\%) & $2(6.1)$ & $8(47.1)$ & $3(18.8)$ \\
Cataract surgery & $12(36.4)$ & $6(35.3)$ & $1(6.3)$ \\
LASIK/LASEK & $9(27.3)$ & $0(0)$ & $0(0)$ \\
Others & $1(3.0)$ & $2(11.8)$ & \\
\hline
\end{tabular}

Values are presented as mean \pm SD 
Table 2 Tear film, ocular surface and meibomian gland status in dry eye patients with ocular neuropathic pain features according to the dominant type of sensitization

\begin{tabular}{|c|c|c|c|c|}
\hline & \multirow[t]{2}{*}{ All } & \multicolumn{3}{|c|}{ Types of sensitization } \\
\hline & & Central $(N=17)$ & Peripheral $(N=16)$ & $p$-value \\
\hline \multicolumn{5}{|c|}{ Tear film and ocular surface parameters } \\
\hline TBUT (sec) & $4.67 \pm 2.01$ & $4.41 \pm 1.77$ & $4.94 \pm 2.26$ & 0.46 \\
\hline Schirmer test score (mm) & $7.22 \pm 5.09$ & $6.82 \pm 2.81$ & $7.56 \pm 6.70$ & 0.68 \\
\hline Corneal staining score (0-9) & $0.42 \pm 0.75$ & $0.38 \pm 0.77$ & $0.43 \pm 0.79$ & 0.41 \\
\hline \multicolumn{5}{|l|}{ MG parameters } \\
\hline MG quality (0-3) & $1.12 \pm 0.82$ & $1.08 \pm 0.76$ & $1.00 \pm 1.00$ & 0.98 \\
\hline MG expressibility (0-3) & $0.61 \pm 0.79$ & $0.54 \pm 0.78$ & $0.43 \pm 0.79$ & 0.76 \\
\hline
\end{tabular}

Data presented as mean \pm SD. TBUT Tear break-up time, MG Meibomian gland.

$p=0.04)$, and patients in the central group spent more time thinking about non-ocular pain than did those in the peripheral group $(0.56 \pm 0.35$ vs. $0.27 \pm 0.26) \quad(p=$ $0.01)$. The scores regarding QoL were highest for reading impairment in both groups, but no significant differences were observed between groups. Although the difference was not statistically significant, most of the QoL scores were higher in the central group (reading, driving, walking, mood, and social activity) than in the peripheral group. The aggravating factors were scored by the percentage of worsening of ocular pain according to mechanical stimuli, such as wind, dry air, heat, and air conditioning, and chemical stimuli, such as volatile chemicals, fumes, and cosmetic fragrances. The associated factors were scored as a percentage of the frequency with which each symptom was accompanied by ocular pain. The percentage values were later divided by 100 for analysis. The values of aggravating and associated factors did not differ significantly between the two groups, except for burning sensation $(0.43 \pm 0.32$ in the peripheral group and $0.73 \pm 0.34$ in the central group; $p=0.01)$.

Table 3 Comparison of Ocular Pain Assessment Survey results between the central-dominant and peripheral-dominant sensitization groups

\begin{tabular}{|c|c|c|c|}
\hline & \multicolumn{3}{|c|}{ Types of sensitization } \\
\hline & Central $(N=17)$ & Peripheral $(N=16)$ & $p$-value \\
\hline \multicolumn{4}{|l|}{ Ocular and non-ocular pain } \\
\hline Pain severity $(0-60)$ & $36.71 \pm 11.48$ & $25.06 \pm 11.21$ & $<0.001$ \\
\hline Pain other than the eyes $(0-10)$ & $6.12 \pm 3.12$ & $3.81 \pm 2.90$ & 0.04 \\
\hline Time spent thinking about non-eye pain (0-1) & $0.56 \pm 0.35$ & $0.27 \pm 0.26$ & 0.01 \\
\hline \multicolumn{4}{|l|}{ Quality of life } \\
\hline Reading & $7.50 \pm 1.73$ & $5.33 \pm 3.08$ & 0.25 \\
\hline Driving & $6.83 \pm 2.17$ & $4.43 \pm 3.31$ & 0.11 \\
\hline Walking & $4.31 \pm 3.68$ & $3.00 \pm 2.08$ & 0.27 \\
\hline Mood & $6.23 \pm 2.98$ & $3.57 \pm 3.41$ & 0.11 \\
\hline Sleep & $3.23 \pm 3.06$ & $3.71 \pm 3.87$ & 0.36 \\
\hline Social activity & $5.69 \pm 2.78$ & $2.71 \pm 3.04$ & 0.20 \\
\hline \multicolumn{4}{|l|}{ Aggravating factors $(0-1)$} \\
\hline Mechanical stimuli & $0.53 \pm 0.32$ & $0.47 \pm 0.39$ & 0.35 \\
\hline Chemical stimuli & $0.55 \pm 0.37$ & $0.36 \pm 0.34$ & 0.85 \\
\hline \multicolumn{4}{|l|}{ Associated factors (0-1) } \\
\hline Redness & $0.28 \pm 0.22$ & $0.44 \pm 0.45$ & 0.84 \\
\hline Burning sensation & $0.73 \pm 0.34$ & $0.43 \pm 0.32$ & 0.01 \\
\hline Photophobia & $0.72 \pm 0.23$ & $0.43 \pm 0.39$ & 0.59 \\
\hline Tearing & $0.67 \pm 0.33$ & $0.27 \pm 0.29$ & 0.74 \\
\hline
\end{tabular}

Data presented as mean \pm SD. 


\section{Discussion}

In the present study, dry eye patients with ocular neuropathic pain features were divided into two groups on the basis of proparacaine challenge test results. Although clinical parameters associated with the tear film and ocular surface, such as TBUT, basal tear secretion, CSS, and MG parameters, were not significantly different between the two groups, the central group complained of more severe ocular pain and non-ocular pain than did the peripheral group. In addition, we noticed that patients in the central group complained of a burning sensation more commonly than did those in the peripheral group.

The underlying mechanisms of DED is ocular surface inflammation and damage induced by tear hyperosmolarity [1]. Tear hyperosmolarity can be a direct cause of ocular discomfort and it can also lead to a death of epithelial cells and a loss of goblet cells and induce ocular discomfort indirectly [1, 19]. However, some patients may suffer from allodynia, hyperalgesia, hypesthesia, and hyperesthesia without any obvious abnormal findings and are thought to have ocular neuropathic pain features $[20,21]$. Ocular neuropathic pain is known to be associated with other systemic diseases such as depression, anxiety, fibromyalgia and headache [6]. It is more frequently reported in females than males [22].

It is well established that structural and functional changes occur in ocular surface sensory nerves in DED. Reduced tear secretion causes stress on ocular mucosal epithelium, leading to local inflammation and peripheral nerve damage [23]. Long-term inflammation and nerve injury alter trigeminal ganglion and brainstem neurons, changing their excitability, connectivity, and impulse firing causing dysesthesias and neuropathic pain referred to the ocular surface [23-25]. Subcategorizing DED patients based on peripheral and/or central dysfunction has important implications in the treatment the disease [26]. Patients with peripheral abnormalities may benefit from treatments targeting ocular surface inflammation and hyperosmolarity whereas patients with neuropathic pain features may need more centrally acting neuromodulators [27].

In vivo confocal microscopy (IVCM) visualizes microstructures, including corneal nerve plexus [28-30]. Some studies have demonstrated the usefulness of the IVCM in evaluating corneal neuropathies by visualizing the decrease in sub-basal corneal nerve density, increase in nerve tortuosity, activation of keratocytes and spindle in corneal stroma, and the presence of microneuromas in the stroma $[11,29,30]$. In many general clinical settings, the IVCM is not available for evaluation.

The $0.5 \%$ proparacaine challenge test is a useful method to assess the central sensitization of ocular pain in a general clinical setting which does not provide research equipments such as esthesiometry or confocal microscopy [10]. In previous studies, patients with complete relief of pain after proparacaine administration were classified into the peripheral sensitization group, those with consistent pain without relief were classified into the central sensitization group, and those with partial relief were classified into the mixed sensitization group [10]. Dieckmann et al. [6] reported that most of the patients showed partial improvement in pain, suggesting that central sensitization and peripheral sensitization were mixed, and the rate of contribution to pain depends on the etiology or duration of the disease. Similarly, in our study, 27 out of 33 (81.82\%) patients showed mixed sensitization. Therefore, for the analysis, we divided the patients into two groups: centraldominant sensitization group with less than 50\% improvement in pain, and peripheral-dominant sensitization group with $50 \%$ or more improvement in pain. No significant differences were observed in pain duration between the two groups. Comorbidities such as CPS, neurologic disorders, and psychological disorders were more common in the central group (70.6\%) than in the peripheral group (37.5\%).

Previous studies have attempted to evaluate patients with ocular pain by using dry eye-related questionnaires, such as the Ocular Surface Disease Index, Dry Eye Questionnaire, and Dry Eye-Related Quality-of-Life Score [13-15]. In many of these questionnaires, ocular pain and dry eye symptoms are queried simultaneously. The Neurobehavioral Rating Scale, which is used as a primary outcome measure for chronic pain, and the Neuropathic Pain Symptom Inventory (NPSI), which is used to evaluate neuropathic pain, have also been used for the evaluation of ocular pain [31, 32]. Recently, the NPSI was appropriately adapted for evaluating ocular pain, and a modified NPSI-Eye was later developed during our study period [33]. Among the available questionnaires, we used the OPAS to evaluate patients with ocular neuropathic pain features, because it provides multidimensional information not only on the severity of ocular pain but also on associated and aggravating factors and the QoL; moreover, it is a validated questionnaire for ocular pain [16]. The Pearson's correlation analysis between the Wong-Baker FACES ${ }^{\oplus}$ Pain Rating Scale and the OPAS score showed good correlation between two measures.

Kalangara et al. [5] used the term "burning eye syndrome" for a subset of dry eye representing a neuropathic pain of the eye. Burning sensation is often diagnosed as neuropathic pain when primary painful conditions are excluded. Burning mouth syndrome (BMS) shares many features with ocular neuropathic pain [34-36]. BMS is characterized by abnormal burning sensation in the oral cavity, but in the absence of clinical 
lesions. Patients diagnosed with BMS have been reported to have psychiatric disorders, such as depression and anxiety, or are mentally vulnerable to stress. In addition, loss of small-diameter nerve fibers in the oral mucosa and decreased brain activation to heat stimuli on functional magnetic resonance imaging have been demonstrated in these patients [36]. Our finding that patients with central-dominant sensitization complained more commonly of a burning sensation may support the association between BMS and ocular neuropathic pain. Further investigations focusing on both the oral mucosal and corneal nervous systems could help identify the underlying mechanism of ocular neuropathic pain.

Our study has several limitations. First, the sample size may not be enough to prove the clinical significance of results. Further studies with larger sample sizes that provide greater power could advance the results of this study. Second, because this study is a multicenter study, subtle bias may be present in conducting clinical examinations. Third, corneal esthesiometry or IVCM imaging were not obtained in this study. Fourth, we used an arbitrary $50 \%$ cut-off value in the proparacaine challenge test for the analysis and it might not be a validated value for determining the types of sensitization. Further studies with more precise diagnostic equipment are warranted in the future.

\section{Conclusion}

In conclusion, dry eye patients with central-dominant sensitization may experience more intense ocular and non-ocular pain than the others. Burning sensation may be a key symptom in ocular neuropathic pain. The OPAS questionnaire can be a good option for evaluating whether patients have ocular neuropathic features. Further investigations on corneal nervous system and peripheral and central sensitization associated with dry eye may give clue to the management of patients with ocular neuropathic pain features.

\section{Abbreviations}

DED: Dry eye disease; OPAS: Ocular pain assessment survey; QoL: Quality of life; TBUT: Tear film break-up time; CSS: Corneal staining score;

MG: Meibomian gland; CPS: Chronic pain syndrome; IVCM: In vivo confocal microscopy; BMS: Burning mouth syndrome
}

\section{Acknowledgements}

This study was supported by a grant of the Korea Health Technology R\&D Project through the Korea Health Industry Development Institute (KHIDI), funded by the Ministry of Health \& Welfare, Republic of Korea (HR20C0021050020) and the Chonnam National University Hospital Biomedical Research Institute (BCRI 19038).

\section{Authors' contributions}

Conceptualization, K.C.Y.; methodology, H.J.Y.; validation, K.C.Y, B.Y.K., and I.C.Y.; formal analysis, J.H.K.; investigation, K.C.Y.; resources, B.Y.K. and I.C.Y.; data curation, K.C.Y, B.Y.K., and I.C.Y.; writing-original draft preparation, J.H.K.; writing-review and editing, J.H.K, K.C.Y, and H.J.Y. All authors have read and agreed to the published version of the manuscript.

\section{Funding}

This research received no external funding.

\section{Availability of data and materials}

Data supporting our findings are contained in the manuscript. However, the raw data set on which the conclusion was made is available on request from Professor Kyung Chul Yoon (contact email: kcyoon@jnu.ac.kr).

\section{Ethics approval and consent to participate}

This study received ethical approval from the Institutional Review Board of the Chonnam National University Hospital. A written informed consent was obtained from all patients before study initiation.

Consent for publication

Not applicable.

\section{Competing interests}

The authors report no conflicts of interest.

\section{Author details}

'Department of Ophthalmology, Chonnam National University Medical School and Hospital, Gwangju, South Korea. ${ }^{2}$ Department of Ophthalmology, Research Institute of Clinical Medicine of Chonbuk National University-Biomedical Research Institute of Chonbuk National University Hospital, Jeonju, South Korea. ${ }^{3}$ Department of Ophthalmology, Konyang University Hospital and College of Medicine, Daejeon, South Korea.

Received: 17 July 2020 Accepted: 12 November 2020

Published online: 18 November 2020

\section{References}

1. Craig JP, Nelson JD, Azar DT, Belmonte C, Bron AJ, Chauhan SK, et al. TFOS DEWS II report executive summary. Ocul Surf. 2017;15:802-12.

2. Craig JP, Nichols KK, Akpek EK, Caffery B, Dua HS, Joo C-K, et al. TFOS DEWS II definition and classification report. Ocul Surf. 2017;15:276-83.

3. Costigan $\mathrm{M}, \mathrm{Scholz} \mathrm{J,} \mathrm{Woolf} \mathrm{CJ.} \mathrm{Neuropathic} \mathrm{pain:} \mathrm{a} \mathrm{maladaptive} \mathrm{response}$ of the nervous system to damage. Annu Rev Neurosci. 2009;32:1-32.

4. Rosenthal P, Borsook D. The corneal pain system. Part I: the missing piece of the dry eye puzzle. Ocul Surf. 2012;10:2-14.

5. Kalangara JP, Galor A, Levitt RC, Felix ER, Alegret R, Sarantopoulos CD. Burning eye syndrome: do neuropathic pain mechanisms underlie chronic dry eye? Pain Med Off J Am Acad Pain Med. 2016;17:746-55.

6. Dieckmann G, Goyal S, Hamrah P. Neuropathic corneal pain. Ophthalmology. 2017;124:S34-47.

7. Andersen $\mathrm{HH}$, Yosipovitch G, Galor A. Neuropathic symptoms of the ocular surface: dryness, pain, and itch. Curr Opin Allergy Clin Immunol. 2017;17: 373-81.

8. Baron R, Binder A, Wasner G. Neuropathic pain: diagnosis, pathophysiological mechanisms, and treatment. Lancet Neurol. 2010;9:80719.

9. Peirs C, Seal RP. Neural circuits for pain: recent advances and current views. Science. 2016;354:578-84.

10. Crane AM, Feuer W, Felix ER, Levitt RC, McClellan AL, Sarantopoulos KD, et al. Evidence of central sensitisation in those with dry eye symptoms and neuropathic-like ocular pain complaints: incomplete response to topical anaesthesia and generalised heightened sensitivity to evoked pain. $\mathrm{Br}$ J Ophthalmol. 2017;101:1238-43.

11. Aggarwal S, Kheirkhah A, Cavalcanti BM, Cruzat A, Colon C, Brown E, et al. Autologous serum tears for treatment of Photoallodynia in patients with corneal neuropathy: efficacy and evaluation with in vivo confocal microscopy. Ocul Surf. 2015;13:250-62.

12. Rosenthal P, Borsook D, Moulton EA. Oculofacial pain: corneal nerve damage leading to pain beyond the eye. Invest Ophthalmol Vis Sci. 2016;57: 5285-7.

13. Vehof J, Kozareva D, Hysi PG, Harris J, Nessa A, Williams FK, et al. Relationship between dry eye symptoms and pain sensitivity. JAMA Ophthalmol. 2013;131:1304-8.

14. Satitpitakul V, Kheirkhah A, Crnej A, Hamrah P, Dana R. Determinants of ocular pain severity in patients with dry eye disease. Am J Ophthalmol. 2017;179:198-204 
15. Galor A, Batawi H, Felix ER, Margolis TP, Sarantopoulos KD, Martin ER, et al. Incomplete response to artificial tears is associated with features of neuropathic ocular pain. Br J Ophthalmol. 2016;100:745-9.

16. Qazi Y, Hurwitz S, Khan S, Jurkunas UV, Dana R, Hamrah P. Validity and reliability of a novel ocular pain assessment survey (OPAS) in quantifying and monitoring corneal and ocular surface pain. Ophthalmology. 2016;123: 1458-68.

17. Miyata K, Amano S, Sawa M, Nishida T. A novel grading method for superficial punctate keratopathy magnitude and its correlation with corneal epithelial permeability. Arch Ophthalmol Chic III 1960. 2003;121:1537-9.

18. Tomlinson A, Bron AJ, Korb DR, Amano S, Paugh JR, Pearce El, et al. The international workshop on Meibomian gland dysfunction: report of the diagnosis subcommittee. Invest Ophthalmol Vis Sci. 2011;52:2006-49.

19. Baudouin C, Irkeç M, Messmer EM, Benítez-del-Castillo JM, Bonini S, Figueiredo FC, et al. Clinical impact of inflammation in dry eye disease: proceedings of the ODISSEY group meeting. Acta Ophthalmol. 2018;96:1119.

20. Mcmonnies CW. The potential role of neuropathic mechanisms in dry eye syndromes. Aust J Optom. 2017;10:5-13.

21. Rosenthal P, Baran I, Jacobs DS. Corneal pain without stain: is it real? Ocul Surf. 2009;7:28-40.

22. Fairweather $D$, Frisancho-Kiss $S$, Rose NR. Sex differences in autoimmune disease from a pathological perspective. Am J Pathol. 2008;173:600-9.

23. Basbaum Al, Bautista DM, Scherrer G, Julius D. Cellular and molecular mechanisms of pain. Cell. 2009;139:267-84.

24. von Hehn CA, Baron R, Woolf CJ. Deconstructing the neuropathic pain phenotype to reveal neural mechanisms. Neuron. 2012;73:638-52.

25. Latremoliere A, Woolf CJ. Central sensitization: a generator of pain hypersensitivity by central neural plasticity. J Pain. 2009;10:895-926.

26. Spierer O, Felix ER, McClellan AL, Parel JM, Gonzalez A, Feuer WJ, et al. Corneal mechanical thresholds negatively associate with dry eye and ocular pain symptoms. Invest Ophthalmol Vis Sci. 2016;57:617-25.

27. Belmonte $\mathrm{C}$. Eye dryness sensations after refractive surgery: impaired tear secretion or "phantom" cornea? J Refract Surg Thorofare NJ 1995. 2007;23: 598-602.

28. Niederer RL, McGhee CNJ. Clinical in vivo confocal microscopy of the human cornea in health and disease. Prog Retin Eye Res. 2010;29:30-58.

29. Ross AR, Al-Aqaba MA, Almaazmi A, Messina M, Nubile M, Mastropasqua L, et al. Clinical and in vivo confocal microscopic features of neuropathic corneal pain. Br J Ophthalmol. 2020;104:768-75.

30. Hamrah P, Qazi Y, Shahatit B, Dastjerdi MH, Pavan-Langston D, Jacobs DS, et al. Corneal nerve and epithelial cell alterations in corneal Allodynia: an in vivo confocal microscopy case series. Ocul Surf. 2017;15:139-51.

31. Jensen MP, Karoly P, O'Riordan EF, Bland F, Burns RS. The subjective experience of acute pain. An assessment of the utility of 10 indices. Clin J Pain. 1989;5:153-9.

32. Bouhassira D, Attal N, Fermanian J, Alchaar H, Gautron M, Masquelier E, et al. Development and validation of the neuropathic pain symptom inventory. Pain. 2004;108:248-57.

33. Farhangi M, Feuer W, Galor A, Bouhassira D, Levitt RC, Sarantopoulos CD, et al. Modification of the neuropathic pain symptom inventory for use in eye pain (NPSI-eye). Pain. 2019;160:1541-50.

34. Bergdahl M, Bergdahl J. Burning mouth syndrome: prevalence and associated factors. J Oral Pathol Med. 1999;28:350-4.

35. Lamey P-J. Burning mouth syndrome. Dermatol Clin. 1996;14:339-54.

36. Jääskeläinen SK. Pathophysiology of primary burning mouth syndrome. Clin Neurophysiol. 2012;123:71-7.

\section{Publisher's Note}

Springer Nature remains neutral with regard to jurisdictional claims in published maps and institutional affiliations.

Ready to submit your research? Choose BMC and benefit from:

- fast, convenient online submission

- thorough peer review by experienced researchers in your field

- rapid publication on acceptance

- support for research data, including large and complex data types

- gold Open Access which fosters wider collaboration and increased citations

- maximum visibility for your research: over $100 \mathrm{M}$ website views per year

At BMC, research is always in progress.

Learn more biomedcentral.com/submissions 